\title{
Lugares de Memória e Turismo Religioso: a Presença de Irmã Dulce em São Cristóvão- Sergipe-Brasil (1933-1934)
}

\section{Places of Memory and Religious Tourism: the Presence of Sister Dulce in São Cristóvão- Sergipe-Brazil (1933-1934)}

\author{
Ivan Rêgo Aragão (ARAGÃO, I. R.) ${ }^{*}$ e \\ José Thiago da Silva Filho (SILVA FILHO, J. T. da) ${ }^{* *}$
}

\begin{abstract}
RESUMO - O centro antigo da cidade de São Cristóvão tem sido destaque por conter elementos que a caracterizam como lugar privilegiado para o desenvolvimento do turismo cultural em Sergipe (Brasil). Essa notoriedade foi ampliada quando a cidade iniciou o processo de reconhecimento da Praça São Francisco à Patrimônio Cultural da Humanidade pela Organização das Nações Unidas para a Educação, Ciência e Cultura. No entanto, um fato olvidado ocorreu no Convento de Nossa Senhora do Carmo da cidade, entre os anos de 1933 e 1934 a Beata Irmã Dulce realizou o noviciado, na Congregação das Irmãs Missionárias da Imaculada Conceição da Mãe de Deus. Nesse sentido, o objetivo principal do presente artigo é apresentar o período de estadia de Irmã Dulce em São Cristóvão, evidenciando o caráter promissor deste fato na formação de um atrativo do Turismo Religioso em Sergipe. A partir de pesquisa biobibliográfica em livros, revistas e monografias, digital em websites, análise documental e trabalho de campo, biografou-se a Beata Irmã Dulce dos Pobres e sua permanência em São Cristóvão, demarcando os lugares de memória potencialmente turistificados.
\end{abstract}

Palavras-chave: Turismo Religioso; Lugares de Memória; Beata Irmã Dulce.

ABSTRACT - The old downtown of São Cristóvão has been featured by contain elements that characterize it as a privileged place for the development of cultural tourism in Sergipe (Brazil). This notoriety was magnified when the city began the process of recognition of São Francisco Square in being a Cultural Heritage of Humanity by the United Nations for Education, Science and Culture. However, a fact that was forgotten occurred at Convento de Nossa Senhora do Carmo in the city. In the years 1933 and 1934, the Blessed Sister Dulce accomplished her novitiate, in the Congregation of Irmãs Missionárias da Imaculada Conceição da Mãe de Deus (Missionary Sisters of Immaculate Conception of Gods' Mother). In this sense, the main purpose of this article is to show the stay period of Sister Dulce in São Cristóvão, highlighting the promising character of this fact in the formation of a Religious Tourism attractive in Sergipe. Using bio bibliography research in books, magazines, journals and papers, digital research in websites, documentary analysis and field work, it was showed some aspects Blessed Sister Dulce's life nun of poor people and her stay in São Cristóvão, demarcating the places of memory with tourist potentiality.

Key words: Religious Tourism; Places of Memory; Blessed Sister Dulce.

\footnotetext{
*Formação: Graduação em Turismo pela Estácio de Sergipe. Especialização em História e Cultura no Brasil pela Universidade Gama Filho (UGF). Mestrado em Cultura e Turismo pela Universidade Estadual de Santa Cruz (UESC-Bahia). Atividade profissional: Professor do Instituto Federal de Sergipe (IFS). Endereço físico para correspondência: Av. Francisco Porto, 239/902. Bairro Jardins. CEP: 49025-230 Aracaju - Sergipe (Brasil). E-mail: ivan_culturaeturismo@hotmail.com

** Formação: Licenciatura em História e Especialização em História Cultural pela Universidade Federal de Sergipe (UFS). Coautor da Proposição de Inscrição da Praça São Francisco para a Lista de Patrimônio da Humanidade. Membro do Instituto Histórico e Geográfico de Sergipe (IHGSE) e do Grupo de Pesquisa Culturas, Identidades e Religiosidades (GPCIR). Endereço físico para correspondência: Praça São Francisco, s./n. CEP: 49100-000 - São Cristóvão - Sergipe (Brasil). Email: thiagofragata@ gmail.com
} 


\section{INTRODUÇÃO}

O centro antigo da cidade de São Cristóvão localizada no estado de Sergipe (Brasil) encontra-se há $25 \mathrm{~km}$ da capital Aracaju. Tendo suas igrejas e casarios escritos de maneira individual no Livro de Tombo desde 1943 pelo Serviço do Patrimônio Histórico e Artístico Nacional - SPHAN ${ }^{1}$, no ano de 1967 recebeu o Tombamento pelo seu conjunto arquitetônico, urbanístico e paisagístico (BRASIL, 2009). Considerada a quarta cidade mais antiga do país (CARVALHO, 1989), possui um rico patrimônio material vinculado tanto ao passado por suas construções coloniais, como por bens culturais de natureza intangível ainda presentes, a exemplo das danças, folguedos, festas religiosas, culinária e música.

Nesse contexto, desde a década de setenta do século passado o centro histórico de São Cristóvão é um atrativo turístico, aonde os visitantes chegam à busca dos pontos da cidade pelo seu potencial histórico-cultural (ARAGÃO, 2009). Até a primeira década dos anos dois mil, eram realizados na parte antiga do núcleo urbano festivais de artes, projetos de música, dança e teatro, figurando o triângulo formado pelas três praças (São Francisco $^{2}$, da Matriz e do Carmo) como lugares de concentração das atividades artístico-culturais.

No entanto, um fato pouco lembrado é a temporada para estudo religioso que Irmã Dulce passou na cidade. Uma passagem curta, mas essencial na vida da religiosa (FRAGATA, 2008). Foi durante esse período que Maria Rita de Souza Brito Lopes realizou noviciado na Escola das Irmãs da Imaculada Conceição, nessa época instalada no Convento de Nossa Senhora do Carmo, em São Cristóvão, recebendo o hábito da Congregação das Irmãs Missionárias da Imaculada Conceição da Mãe de Deus. (FRAGATA, 2008)

Dessa forma, o presente artigo tem como objetivo principal desvelar a relação da Irmã Dulce e São Cristóvão, evidenciando o caráter promissor deste fato na formação de um atrativo vinculado ao Turismo Religioso em Sergipe. A partir de pesquisa biobibliográfica em livros, revistas e monografias, digital em websites, análise

\footnotetext{
${ }^{1}$ Atual Instituto do Patrimônio Histórico e Artístico Nacional.

${ }^{2}$ A Praça São Francisco é Patrimônio Cultural da Humanidade, título chancelado pela UNESCO por ser um modelo de Plaza Mayor fora da Espanha e de suas colônias espanholas (ARAG ̃̃O, 2011).
} 
documental e trabalho de campo, biografou-se a Beata Irmã Dulce dos Pobres e sua permanência em São Cristóvão, demarcando os lugares de memória a ela referenciados. Locais estes, potencialmente turistificados, tais como, o Convento do Carmo com a gruta/horto de oração que leva o seu nome e a sala do memorial dedicada a Irmã Dulce. Ela foi beatificada em 2011, podendo tornar-se a primeira santa católica brasileira ${ }^{3}$.

\section{ASPECTOS HISTÓRICOS, CULTURAIS E TURÍSTICOS DE SÃo CRISTÓVÃo}

Na sede de São Cristóvão, verifica-se o trabalho vinculado à imagem de uma cidade que possui o seu centro antigo com fortes indícios do patrimônio históricocultural brasileiro. Sempre relacionado aos elementos culturais, o núcleo histórico da cidade, já abrigou dois projetos de enaltecimento das artes, incentivando a visitação do lugar.

De 1972 até o ano de 2005, São Cristóvão era o cenário do Festival de Arte (MENEZES, 2007). O FASC foi uma ideia da Universidade Federal de Sergipe para homenagear os 150 anos da Independência do Brasil (FONTES, 2007). Ainda de acordo com Fontes (2007, p. 8), o festival foi criado por duas razões: "[...] a primeira, ser uma cidade histórica, com arquitetura de grande beleza, ex-capital. A segunda, seu campus está no município de São Cristóvão. O festival iria, então, finalizar o seu compromisso com a cultura, a arte e a história. Era o ano de 1972".

Dentro da programação do festival, era possível assistir a concertos de música erudita, corais, orquestras, grupos com diversos instrumentos musicais, trios, quartetos e bandas sinfônicas, além de cantores e grupos de música da MPB (FONTES, 2007). Juntamente com o teatro e música, outras expressões artísticas se faziam presentes no evento, como os grupos de balé e dança contemporânea, exposições de pintura, escultura e fotografia. Os grupos folclóricos se apresentavam pelas ruas da cidade (FONTES, 2007).

O FASC por mais de três décadas estimulou a cultura brasileira com artistas locais e de várias partes do país, onde por todo o centro histórico havia apresentações

\footnotetext{
${ }^{3}$ Fonte: <http://www.irmadulce.org.br/>.
} 
culturais (MENEZES, 2007). Ainda segundo Menezes (2007, p. 17), "eventos culturais como o Festival de Arte de São Cristóvão, fazem a população reconhecer as marcas do seu patrimônio, encontrar e partilhar com pessoas de outras regiões essa experiência cultural, resultando no fortalecimento de sua identidade".

No período de 2001 a 2004, a cidade desenvolveu o projeto "São Cristóvão, Cidade da Seresta" (SOUZA, 2004). O projeto em questão, era formatado com o intuito de realizar um cortejo de seresteiros pelo centro histórico com paradas em pontos estratégicos das ruas, trazia também a apresentação de grupos folclóricos, músicos da terra e cantores nacionais (SOUZA, 2004).

Além de eventos culturais agregados ao patrimônio arquitetônico da cidade, São Cristóvão detém manifestações vivas e pulsantes da cultura popular com grupos de danças e folguedos. Não somente pela influência ibérica, as manifestações do patrimônio imaterial de São Cristóvão, receberam referências culturais africanas e indígenas. São perceptíveis os aspectos influenciados pelas etnias do índio, africano e português no folclore do Reisado, São Gonçalo, Samba de Coco, Caceteira, Batalhão de São João, Taieiras, Langa e Bacamarteiros. Os instrumentos musicais como o cavaquinho, sanfona, pandeiro e bumbos, dentre outros, definem os sons e ritmos dessas danças e folguedos, acompanhados pelo batuque, marchas e cantos.

Essas danças, que foram consideradas profanas por muitos anos e recriminadas pela Igreja, possuem no seu interior, o louvor aos santos católicos (FONTES, 2007). Sobre as danças e folguedos, Fontes (2007, p. 16) comenta que:

[...] o Brasil recebeu uma forte contribuição ibérica, resultante dessa unificação na nossa cultura popular, que fecundou nossos folguedos e danças com a nostalgia dos benditos, os sapateados e volteios do Guerreiro, sem falar a deslizante beleza das marchas do Reisado e Pastoril nem o ritmo marcante dos bombos e flautas das zabumbas, plasmado pela mistura de etnias.

Assim como a culinária do doce desenvolvida na cidade por gerações pela formação dos engenhos de açúcar no entorno da sede da cidade. Embora o açúcar em Sergipe alcançasse grande produção no século XIX - diferentemente de Alagoas e Pernambuco - desde o período colonial existiam engenhos em São Cristóvão espalhados pela região estimulando a produção de uma alimentação à base de cana-de-açúcar (NUNES, 2007). Há que se destacar também uma marcante gastronomia a base do coco que é abundante na região. 
O que se constata no cotidiano sancristovense é a produção de uma culinária à base de açúcar consumida tanto pela população local como por quem chega à cidade. As queijadinhas $^{4}$, biscoitos de goma, bolachinhas, briceletes ${ }^{5}$, beijus, bolos e sarolhos ${ }^{6}$ compõem um dos elementos da memória afetiva e gastronômica da população e conferem identidade cultural ao município. Suas receitas são passadas de geração a geração, são tradutoras do conhecimento local. Este saber fazer se configura como transmissor de experiências sociais e de sabedoria, que são comuns à coletividade local (THOMPSON, 1998).

No centro histórico de São Cristóvão, sempre no segundo final de semana após o Carnaval, é realizada a Festa do Senhor dos Passos considerada a segunda maior romaria do nordeste no período da Quaresma (ARAGÃO, 2013). Nesse contexto, a cidade possui um rico patrimônio cultural que abrange os elementos em pedra e cal, as danças e folguedos populares, a culinária do doce e também de ritos católicos sagrados.

Considerada uma cidade que se encontra no perímetro da grande Aracaju, constatam-se passeios diários realizados por agências de viagens e receptivo turístico em que o visitante chega à cidade e passa parte do dia. No entanto, o centro antigo da cidade possui restaurantes self services, equipamentos de hospedagem, como a pousada situada nas dependências do convento Lar Imaculada Conceição, antiga Santa Casa de Misericórdia $^{7}$ (Figura 1), possibilitando que o turista pernoite no local e fique hospedado num templo do século XVII, na Praça São Francisco patrimônio cultural da humanidade. Além de lojas de artesanatos (bonecos de pano e barro, objeto em madeira, xilogravura, cordel).

\footnotetext{
${ }^{4}$ Originalmente feita com queijo, às queijadinhas foram trazidas pelos portugueses que vieram para São Cristóvão, sendo criativamente incorporadas e adaptadas conforme os preceitos locais. O queijo foi substituído pelo coco - matéria prima abundante no litoral do Nordeste do Brasil (FONTES, 2007).

5 Tradicionais biscoitos feitos pela Congregação das Irmãs Missionárias Lar Imaculada Conceição. Possuem várias capas e são elaborados com suco de laranja e raspas de limão (FONTES, 2007).

${ }^{6}$ Espécie de beiju arredondado.

${ }^{7}$ Em 2011 a antiga Santa Casa ou Lar Imaculada Conceição, como é mais conhecida, foi restaurada pelo Instituto do Patrimônio Histórico e Artístico Nacional - IPHAN para também funcionar como hospedaria. (Portal IPHAN, 2015).
} 


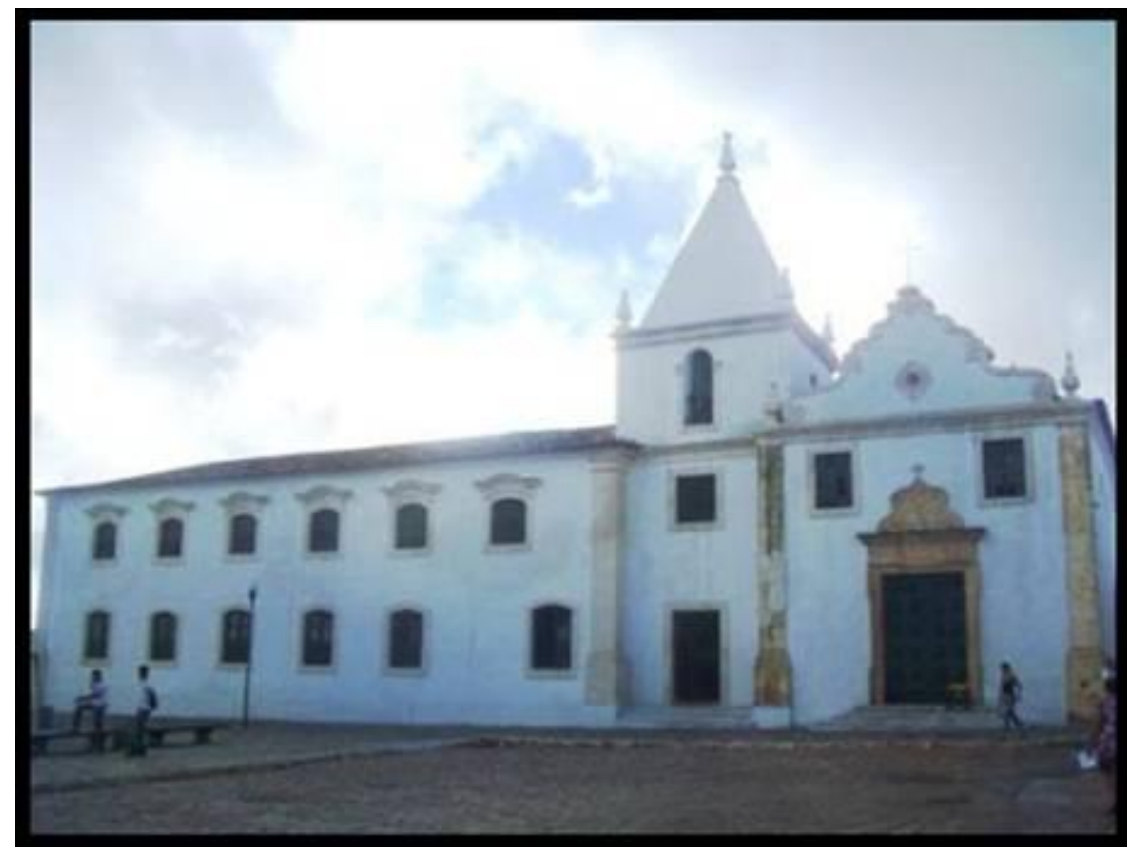

FIGURA 1 - LAR IMACULADA CONCEIÇÃO.

Foto: José Thiago da Silva Filho, 2015.

Estas são algumas peculiaridades de São Cristóvão, que a configuram como destino do turismo cultural. No entanto, intentou-se destacar a presença de Irmã Dulce e seus lugares de memória.

\section{IRMÃ DULCE EM SÃO CRISTÓVÃO}

Maria Rita de Souza Brito Lopes Pontes (Irmã Dulce) nasceu na cidade de Salvador em 26 de maio de 1914 (Figura 2) (ISTO É, 2000). Aos sete anos perde sua mãe e realiza sua primeira comunhão na Igreja Santo Antônio (ISTO É, 2000). Aos 19 anos, em fevereiro de 1933:

[...] logo após a sua formatura como professora, Maria Rita entra para a Congregação das Irmãs Missionárias da Imaculada Conceição da Mãe de Deus, na cidade de São Cristóvão, em Sergipe. Em 13 de agosto de 1933, recebe o hábito de freira das Irmãs Missionárias e adota, em homenagem a sua mãe, o nome de Irmã Dulce. ${ }^{8}$

\footnotetext{
${ }^{8}$ Disponível em: <www.irmadulce.org.br〉. Acesso em: 15/01/2015.
} 


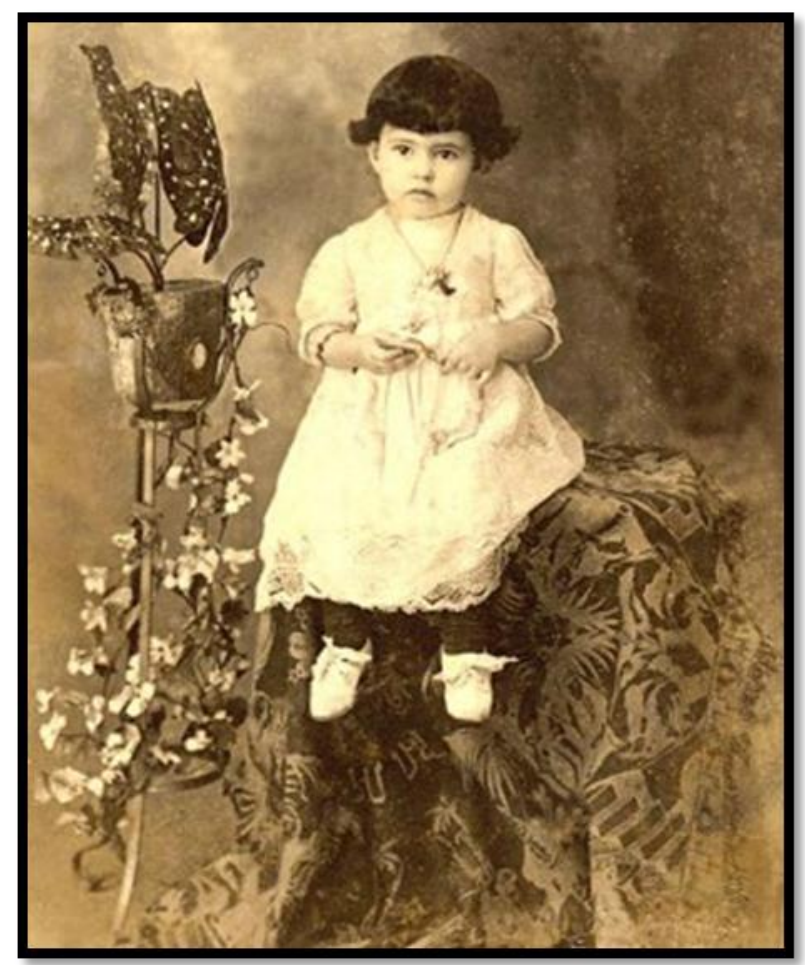

FIGURA 2 - MARIA RITA (IRMÃ DULCE) CRIANÇA.

Fonte: www.irmadulce.org.br, 2016.

Volta a Salvador onde de 1935 a 1992 (ano do seu falecimento) dedica sua vida para cuidar dos pobres e doentes (ISTO É, 2000). No ano de 1988 foi indicada ao Prêmio Nobel da Paz (ISTO É, 2000). Em 2011, Irmã Dulce foi beatificada pelo Papa Bento XVI por ter um milagre creditado pela sua interseção. O fato aconteceu na cidade sergipana de Itabaiana e foi reconhecido pela Comissão Eclesiástica do Vaticano ${ }^{9}$. A notícia do reconhecimento do primeiro milagre da Beata Irmã Dulce dos Pobres ${ }^{10}$ trouxe uma maior visibilidade a religiosa já amada na Bahia desde a década de 60 do século passado.

No entanto, é de pouco conhecimento que Irmã Dulce realizou seus primeiros estudos religiosos na cidade de São Cristóvão em Sergipe (FRAGATA, 2008). Ela foi postulante e noviça na Escola da Congregação das Irmãs Missionárias da Imaculada Conceição da Mãe de Deus (FRAGATA, 2008). Espaço que abriga até a atualidade, as

\footnotetext{
${ }^{9}$ Disponível em: <http://g1.globo.com/bahia/noticia/2011/05/identidade-da-mulher-que-recebeu-milagrede-irma-dulce-e-revelada.html >. Acesso em: 13/01/2015.

${ }^{10}$ Nome de beatificação de Irmã Dulce.
} 
igrejas das ordens segunda e terceira carmelita, além, da edificação conventual ${ }^{11}$. O rito da sua nova vestição deu-se na manhã do dia 15 de agosto de 1933, quando recebeu o hábito e o nome Dulce em homenagem a mãe falecida. (Figura 3) (FRAGATA, 2008).

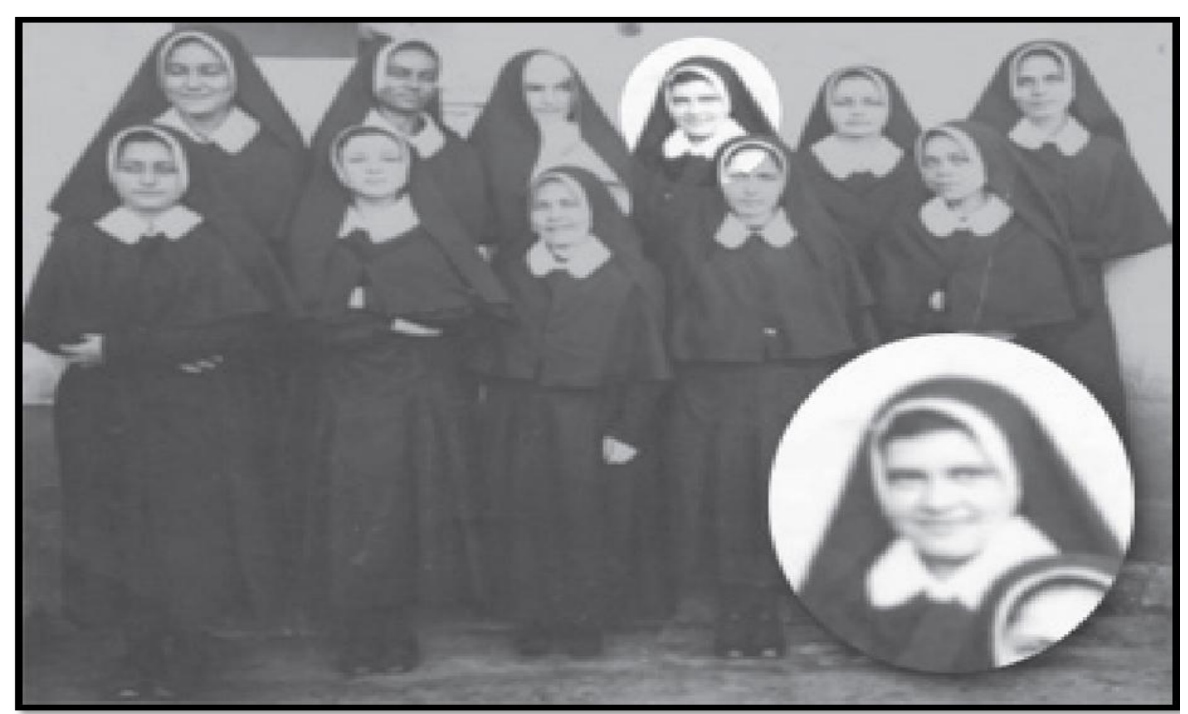

FIGURA 3 - IRMÃ DULCE COM A CONGREGAÇÃO DAS IRMÃS MISSIONÁRIAS DA IMACULADA CONCEIÇÃO DA MÃE DE DEUS EM SÃO CRISTÓVÃO/SE.

Fonte: Acervo das Obras Sociais Irmã Dulce, 1934.

Dulce permaneceu em São Cristóvão entre nove de fevereiro de 1933 e quinze de agosto de 1934 (FRAGATA, 2008). Ainda de acordo com Fragata (2008), nesse período, escreveu três cartas e memórias sobre a cidade destinadas a Maria Imaculada de Jesus, nome de Elisabeth Maria Gertrudes Tombrock, fundadora e Madre Superiora da Congregação das Irmãs Missionárias da Imaculada Conceição (IMIC), que estava no Convento de São Boaventura, em Nova York ${ }^{12}$.

O tema das correspondências é bem diverso. Ela expõe o contentamento em estar no Convento do Carmo, a emoção e gratidão por vestir o hábito com as cores da vestimenta de Nossa Senhora, a satisfação do novo batismo com o nome da sua mãe e, por fim, sua profissão e votos (FRAGATA, 2008). Na primeira carta, Irmã Dulce registra que tem “[...] immenso prazer, de vos escrever, do meu tão desejado Convento do

\footnotetext{
${ }^{11}$ O Convento do Carmo nem sempre foi de uso da ordem carmelita, além da Congregação da Imaculada Conceição, outras ordens femininas tiveram sua jurisdição no século XX: Clarrissas Concepcionistas e Beneditinas Enclausuradas. Somente no ano de 2003 é que a ordem Carmelita reassumiu a posse do centenário monumento tombado pelo IPHAN em 1943 (FRAGATA, 2009).
}

12 Disponível também em: <http://br.monografias.com/trabalhos913/cartas-irma-dulce/cartas-irmadulce.shtml>. Acesso em: 13/01/2015. 
Carmo". ${ }^{13} \mathrm{Na}$ segunda, a religiosa registra que se encontra com grande alegria ao escrever:

[...] a bôa Madre, do querido e desejado Noviciado. Quanto é bom o nosso Jesus, em conceder esta graça, tão significante, a mim pobre creatura, escolhendo-me para ser sua noivinha! Sinto-me tão feliz, minha bôa mãesinha, por pertencer a nossa Congregação e de vestir o habito, que representa as côres da vestimenta da nossa Mãe do Céo! ${ }^{14}$

O epistolário se encontra arquivado nas Obras Sociais Irmã Dulce em Salvador ${ }^{15}$ e integraram o processo histórico de Beatificação de Irmã Dulce, desvelando "o cotidiano, os afazeres, as brincadeiras, a homilia e a visão de mundo da adolescente Maria Rita Lopes Pontes durante a primeira fase da sua formação religiosa" (FRAGATA, 2008, p. 341). Na terceira e última missiva, a religiosa comenta:

[...] Reverenda Madre, quero dizer-vos a grande graça, que Jesus me deu, de eu fazer a Santa Profissão, na presença do meu papai, que Jesus trouxe para assistir o grande dia! E mais do que isto, fiquei alegre, por ve-lo receber o meu Divino Esposo, na Santa Communhão. Sim, logo depois que o Santissimo ficou Exposto, papai o recebeu em seu coração. Elle ficou aqui até a Quinta-feira, e d'aqui, seguio para Aracajú, indo de lá a Recife e a Maceió, depois voltará a Bahia. ${ }^{16}$

Percebe-se a relevância das cartas principalmente por ilustrar os primeiros anos da beata ao se inserir na vida religiosa em contato com a cidade histórica sergipana. Nesse contexto, as cartas de Irmã Dulce são instrumentos de comunicação que:

[...] constitui fonte preciosa de informações aos historiadores. De forma explícita (datas, nomes, local etc) ou implicitamente (cotidiano, liturgia, o silêncio etc) as impressões facultam substanciar pesquisas diversas. Numa linguagem cinematográfica, a narrativa revela flashes de uma vida que teve São Cristóvão como cenário (FRAGATA, 2008, p. 344).

\footnotetext{
${ }^{13}$ Carta de Irmã Dulce para Elisabeth Maria Gertrudes Tombrock. São Cristóvão, 19 de março de 1933. Salvador, Arquivo das Obras Sociais Irmã Dulce.

${ }^{14}$ Carta de Irmã Dulce para Elisabeth Maria Gertrudes Tombrock. São Cristóvão, 27 de agosto de 1933. Salvador. Arquivo das Obras Sociais Irmã Dulce.

${ }^{15}$ A sede das Obras Sociais de Irmã Dulce está localizada à Av. Bonfim, n. 161, Largo de Roma em Salvador-Bahia.

${ }^{16}$ Carta de Irmã Dulce para Elisabeth Maria Gertrudes Tombrock. São Cristóvão, 18 de agosto de 1934. Salvador, Arquivo das Obras Sociais Irmã Dulce.
} 
No curto período de tempo que Irmã Dulce permaneceu em São Cristóvão, estabeleceu uma rotina de estudos e pequenos afazeres diários, vistos pela neófita "[...] como pequeninos atos de amor que realiza feliz como uma criançinha" (FRAGATA, 2008, p. 343). A presença da sua boneca denominada de Célica e o brincar no ambiente austero do convento aguardam outro trabalho acadêmico. Além disso, a passagem da religiosa pela cidade estabeleceu lugares vinculados à sua memória e, que se tornaram pontos de atração potencialmente turistificados de quem visita o centro antigo, a exemplo do Convento do Carmo e suas dependências e da sala do memorial dedicado a ela.

O conjunto carmelita com igrejas da ordem segunda e terceira e convento, é o principal objeto das lembranças, inclusive, de quem conviveu com a religiosa baiana. Em entrevista, a senhora Olga Braga dos Santos, 93 anos, conta que: “[...] grande amiga da noviça Maria Rita, lembra emocionada dos seus afazeres, como tocar o sino, tirar água da fonte, limpar o chão, das orações; lembra ainda da boneca Célica, o brinquedo inseparável da religiosa baiana" ${ }^{\prime 17}$.

No depoimento da Irmã Maria das Neves "o sítio" era o lugar do lazer, dos risos, da comunicação, das brincadeiras, mas também da oração. No interior do secular convento as práticas pediam austeridade, o voto de silêncio era frequente (FRAGATA, 2008). A partir do contexto da vida e memória de Irmã Dulce apresentam-se os locais anteriormente mencionados como espaços potenciais de atração do turismo religioso em São Cristóvão.

\section{LUGARES POTENCIALMENTE TURISTIFICADOS EM SÃO CRISTÓVÃO E O TURISMO RELIGIOSO}

O turismo desponta como um conjunto de atividades que vão além dos fatores vinculados à economia, lazer e educação. O mesmo converge para ações de preservação do patrimônio cultural, resgate da memória e valorização das manifestações culturais religiosas dos indivíduos nas sociedades. É nesse contexto que Pérez (2009, p. 8) informa que "o turismo como um fenômeno sociocultural complexo não deve ser só

\footnotetext{
${ }^{17}$ Olga Braga dos Santos entrevista concedida a José Thiago da Silva Filho. São Cristóvão, 14/11/2006.
} 
medido estatisticamente, como também interpretado qualitativamente na sua complexidade humana".

Quando se biografa pessoas, as suas lembranças e ações, buscando transformálas em atrativos, a atividade no campo do turismo religioso percebe o poder de mobilidade por parte de religiosos notórios pelo seu exemplo em vida. Para Dias (2003, p. 17):

O turismo religioso apresenta características que coincidem com o turismo cultural, devido à visita que ocorre num entorno considerado como patrimônio cultural, os eventos religiosos constituem-se em expressões culturais de determinados grupos sociais ou expressam uma realidade histórico-cultural expressiva e representativa de determinada região.

Nesse sentido, santuários, festas, santos e beatos, têm sido vistos por parte dos órgãos oficiais do turismo no mundo e no Brasil ${ }^{18}$ como locus de atração de diversos grupos de turistas para os locais-sede.

\section{1 - O CONVENTO DO CARMO}

A passagem de Irmã Dulce por São Cristóvão para os estudos do noviciado produziu lugares de memória da religiosa que são potencialmente atrativos para quem é devoto da beata ou possui curiosidade em conhecer a sua biografia. Esses locais que reportam a vida de Irmã Dulce são relevantes, na medida em que, traduzem a necessidade humana de estabelecer espaços de referência, numa tentativa de preservar o passado como herança e conservar a identidade cultural (NORA, 1993). Os lugares de memória são na concepção de Pollack (1992, p. 5) “[...] um elemento constituinte do sentimento de identidade, [...] na medida em que ela é também um fator extremamente importante do sentimento de continuidade e de coerência de uma pessoa ou grupo em sua reconstrução de si”. Dessa forma, o Conjunto Carmelita com a igreja, convento, gruta/horto e a sala dedicada à memória de Irmã Dulce, apontam para lugares atrativos para o turismo religioso, não somente pela beleza artística e arquitetônica do patrimônio construído, mas por ser local de passagem da religiosa.

\footnotetext{
${ }^{18}$ Em 2013 o Ministério do Turismo no Brasil abriu edital de apoio para locais que possuíam potencial para desenvolver o turismo religioso nas cinco regiões do país, sendo a cidade de São Cristóvão uma das semifinalistas (MINISTÉRIO DO TURISMO).
} 
O conjunto carmelita edificado por esta Ordem religiosa católica é composto pela igreja do Carmo Grande tendo a esquerda o convento e a direita antiga igreja da Ordem $3^{\text {a }}$ do Carmo, conhecida como Carmo Pequeno ou Igreja do Senhor dos Passos. Para alguns pesquisadores da arte colonial $^{19}$, a Igreja Conventual do Carmo foi a primeira a ser edificada do conjunto carmelita.

Construído no século XVIII pelo frei Antônio de Santa Eufrásia Barbosa (ORAZEM, 2006), o monumento tem o frontão ${ }^{20}$ em estilo barroco decorado em pedra calcária ostentando o escudo da Ordem Carmelita. A fachada possui três arcos de entrada para a galilé ${ }^{21}$ e o mesmo número de janelas na altura do coro (ORAZEM, 2006). Segundo Carvalho (1989), no passado, a igreja possuía seis altares com os retábulos em talha dourada do século XVIII, mas atualmente possui apenas um original. Merece destaque os elementos artísticos fitomórfos, concheados e volutas na sua fachada (Figura 4).

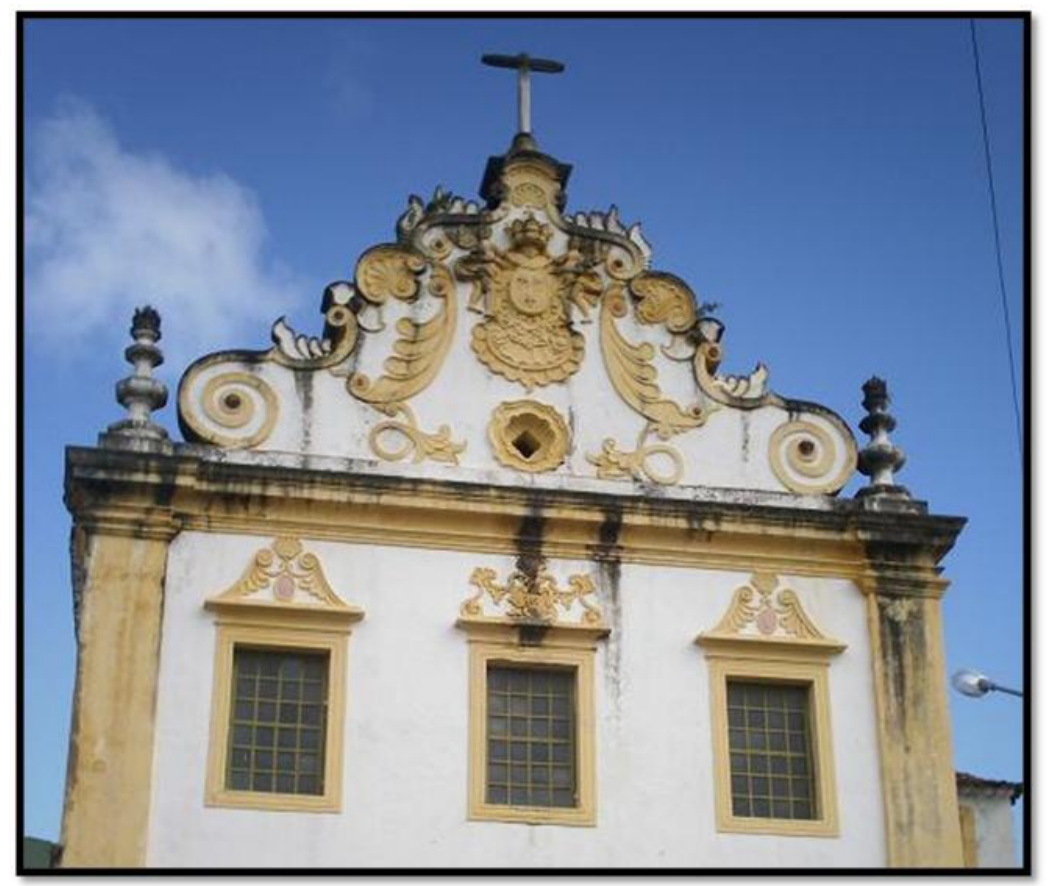

FIGURA 4 - FACHADA DA IGREJA DO CARMO.

Foto: Ivan Rêgo Aragão, 2007.

\footnotetext{
${ }^{19}$ Bazim (1983), Carvalho (1989), Nascimento (1981), Orazem (2006).

${ }^{20}$ Conjunto arquitetônico de forma triangular que decora o topo da fachada principal de um edifício.

${ }^{21}$ Elemento da igreja que remete a galeria entre a parede do frontispício e a porta da nave.
} 
No entanto, o convento construído pelos carmelitas nem sempre foi morada e escola exclusiva desta ordem religiosa. Tem-se que na segunda metade do século XIX a ordem carmelita foi obrigada a retirar-se de seus templos brasileiros, diante do conflito estabelecido com o Imperador D. Pedro II no episódio que ficou conhecido como Questão Religiosa. Isso justifica a instalação da escola da Congregação da Imaculada Conceição que abrigou Irmã Dulce ainda jovem (FRAGATA, 2008).

Pertinente informar que outras ordem femininas também tiveram uma passagem no convento: Irmãs Clarissas Concepcionistas e Beneditanas Enclausuradas (FRAGATA, 2008). Somente no ano de 2003, os carmelitas voltaram a usar o templo de São Cristóvão, instalando nele a Escola de Formação Carmelita Internacional. Foi na gestão do Prior João Costa que se deu a implantação do Memorial Irmã Dulce, numa das salas do convento em 2009 (Figura 5) ${ }^{22}$.

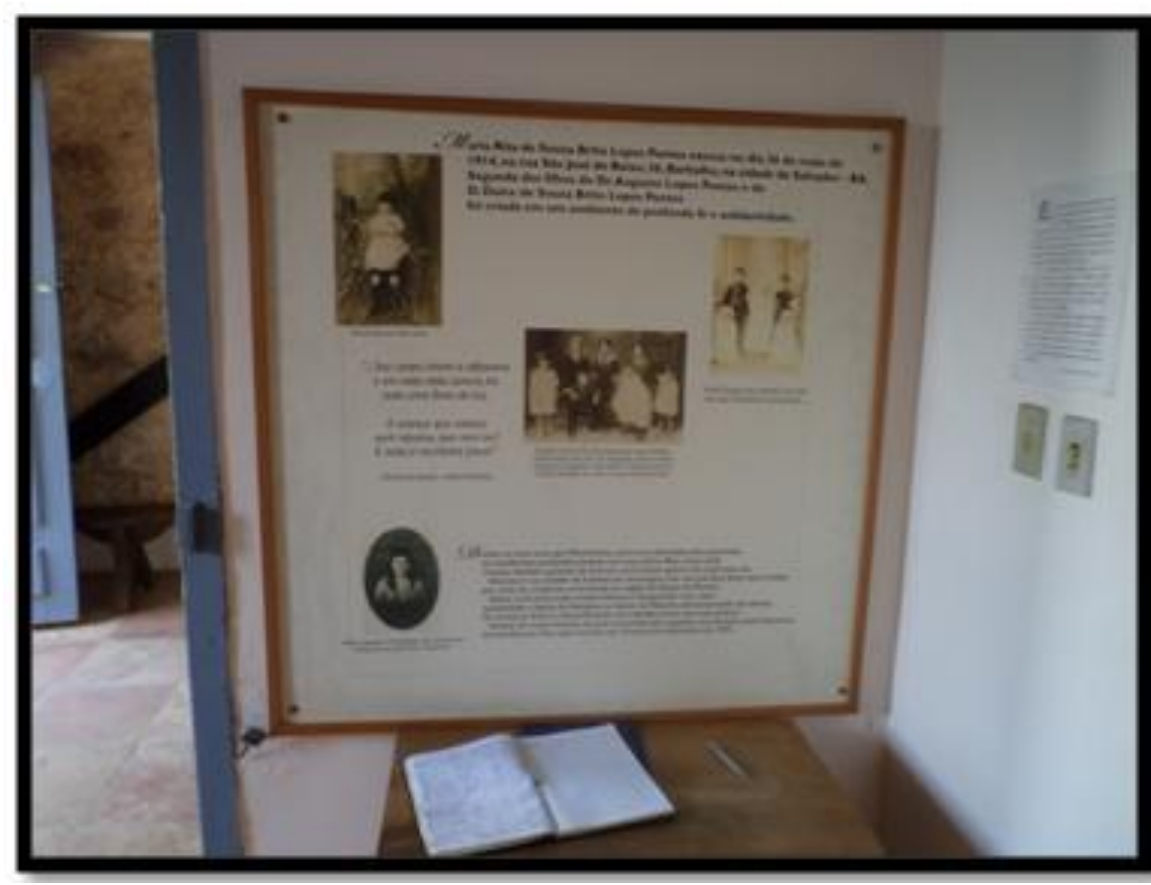

FIGURA 5 - PAINEL NO MEMORIAL DE IRMÃ DULCE.

Foto: Ivan Rêgo Aragão, 2014.

\subsection{MEMORIAL IRMÃ DULCE}

Demarcar a trajetória de vida da Irmã Dulce a partir dos lugares em que esteve e das lembranças de quem dividiu momentos com ela foi o desafio abraçado pelas Obras

\footnotetext{
${ }^{22}$ Fonte: <http://www.turismosergipe.net/>.
} 
Sociais Irmã Dulce, mantenedora da missão e memória da religiosa ${ }^{23}$. Reconhecendo o Convento do Carmo, de São Cristóvão, como lugar de sua formação, é que a instituição sediada em Salvador estabeleceu parceria com os carmelitas para instalação de um pequeno memorial contando sua vida e presença na década de 1930.

Uma biografia a partir de textos e imagens, além de réplicas de seu hábito, da boneca Célica que ilustrou tantas cenas cotidianas, figuram na exposição (Figura 6). Para além da pequena sala Irmã Dulce, as dependências de todo o complexo carmelita devem ser compreendidas como memorial. O claustro e seu jardim, a gruta, assim como o sino e mesmo a cela (seu quarto) permanecem nos relatos e lembranças. É possível encontrar o convento descrito pela Irmã das Neves:

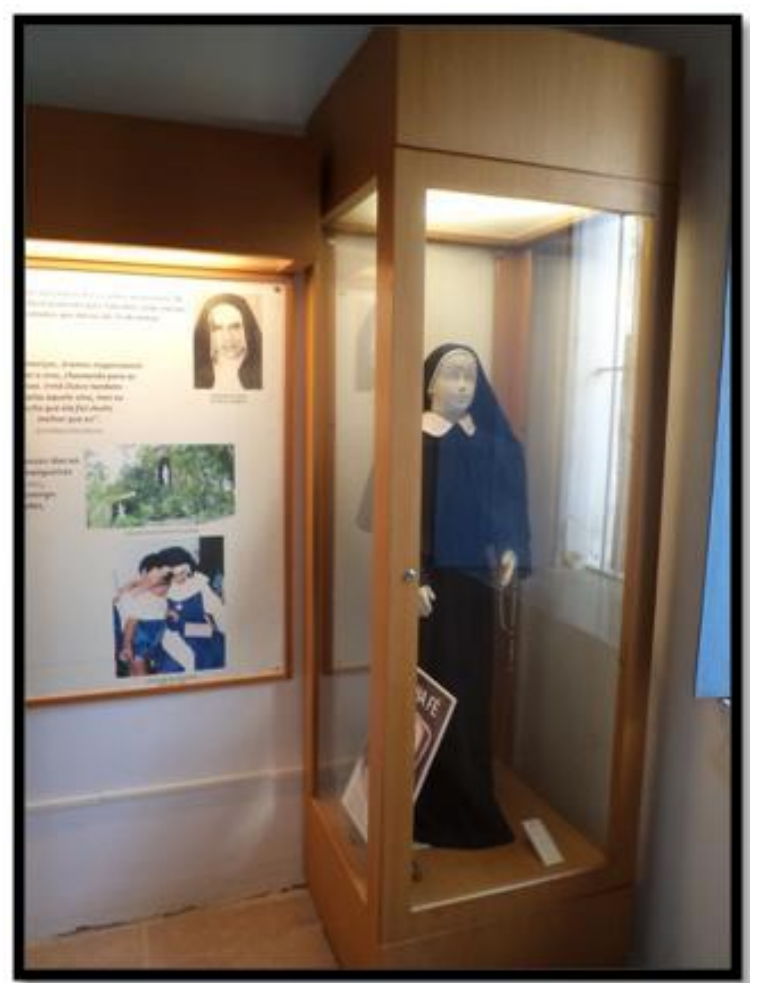

FIGURA 6 - REPLICA DO HABITO DE IRMÃ DULCE DA CONGREGAÇÃO DAS IRMÃS MISSIONÁRIAS DA IMACULADA CONCEIÇÃO DA MÃE DE DEUS

Foto: Ivan Rêgo Aragão, 2014.

\subsection{HORTO IRMÃ DULCE}

Atualmente, o lugar é chamado de Gruta de Oração da Irmã Dulce pelos moradores (Figura 7). Desde os tempos da noviça era usado para meditações e orações,

\footnotetext{
${ }^{23}$ Fonte: <http://www.irmadulce.org.br/>.
} 
Seu pai, Dr. Augusto, teria levado dali algumas folhas e flores na ocasião da sua vestição, no dia 15 de agosto de $1934^{24}$. Trata-se de uma elevação escavada num ambiente arborizado, com fonte e pedras compondo o nicho. Nele, a representação da imagem de Nossa Senhora de Fátima e as crianças que testemunharam o milagre em Portugal.

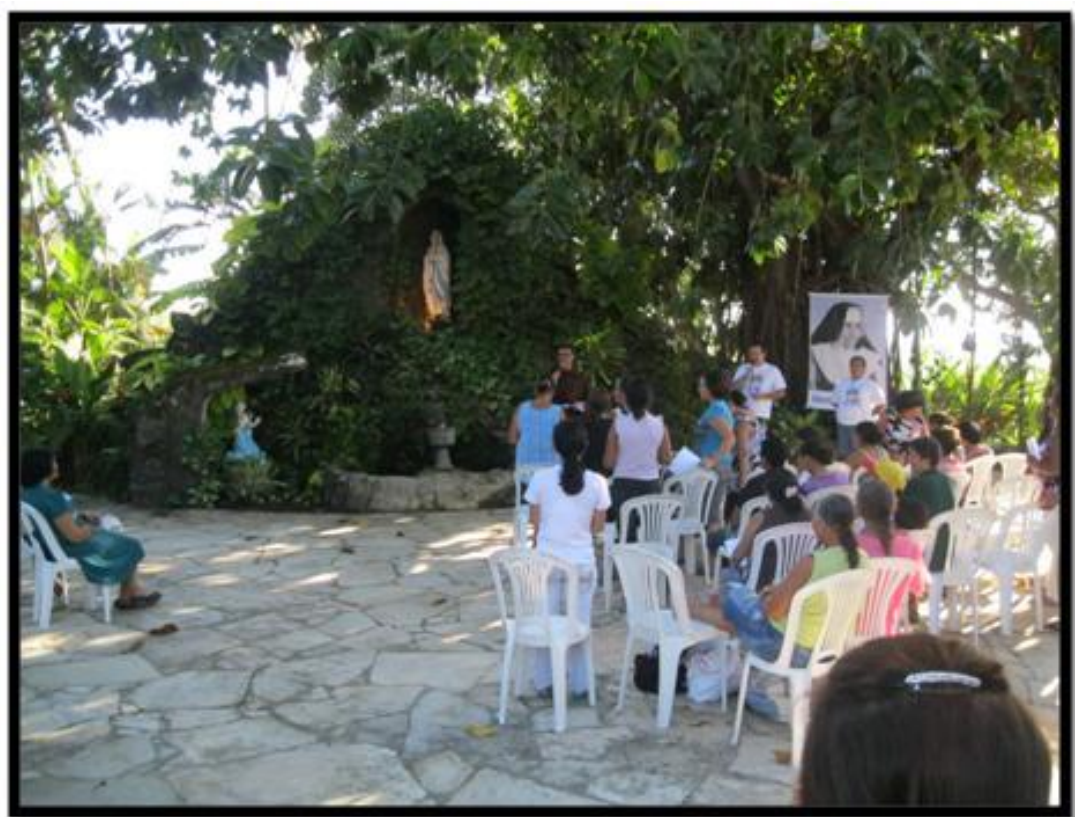

FIGURA 7 - GRUTA DE IRMÃ DULCE.

Foto: Ivan Rêgo Aragão, 2011.

\section{CONSIDERAÇÕES FINAIS}

A presença da Irmã Dulce no complexo arquitetônico do século XVIII é passível de demarcação, seja a partir das lembranças dos que dividiram com ela o convívio em um ano e meio do seu postulantado e noviciado, seja a partir dos documentos gerados, dos suportes que concretizaram o Memorial Irmã Dulce em 2009, um lugar para lembrar quem foi “o Anjo Bom da Bahia”. Dona Olga Braga dos Santos (1922/2015) colaborou na inauguração do espaço museal que parece pequeno ao visitante, ela sempre morou vizinha ao Convento e ainda menina recepcionou Maria Rita Lopes Pontes quando ela chegou na manhã de 9 fevereiro de 1933 (FRAGATA, 2008). No seu depoimento, recorda da religiosa baiana: "Ela simpatizou comigo [...] como a madre me deixava

\footnotetext{
${ }^{24}$ Carta de Irmã Dulce para Elisabeth Maria Gertrudes Tomblock, de 18 de agosto de 1934. Arquivo das Obras Sociais Irmã Dulce.
} 
entrar eu ajudava as freiras nas atividades diárias [...] chorei tanto quando ela foi embora que pensei que ia morrer" 25 .

O rito de lembrar, a necessidade ou a possibilidade de reconstituir os afetos e os dias de Irmã Dulce no convento secular recebeu, portanto um altar, um centro de referência ou um lugar de memória que deve transpor as paredes da "salinha" afinal as pessoas são portadoras de lembranças e de conhecimentos. “Os lugares de memória são, antes de tudo, restos. A forma extrema onde subsiste uma consciência comemorativa numa História que a chama, porque ela a ignora" assegura Nora (1993, p. 12). No entanto esses locais de memória relacionados à irmã Dulce, se presentificam pela lembrança individual e coletiva, sendo o ato de rememorar compartilhado através das mesmas experiências (HALBWACHS, 2004).

A incorporação do lugar de memória sobre Irmã Dulce e a oferta turística local potencializam o turismo religioso em São Cristóvão/SE. Essa forma de turismo como um retorno do indivíduo para dentro de si, "e por isso mesmo marcado por um exercício de plena inversão: visitar santuários (tradicionais ou profanos) significa voltar ao lugar de identidade" (OLIVEIRA, 2005, p. 339). A atividade turística entendida como um dos principais fatores do trânsito, deslocamento ou mobilidade humana, configura-se como atividade marcadamente cultural, impulsionado pelo desejo dos grupos sociais em vivenciar experiências diferenciadoras de seu cotidiano, projetando, dessa forma, o patrimônio cultural como instrumento mediador de aprendizagem e educação (COSTA, 2009).

Para o devoto, estudante, pesquisador, turista ou mesmo morador de São Cristóvão, o exercício de visitar o convento do Carmo e suas dependências (claustro, igreja, gruta etc.), significa perceber Irmã Dulce no lugar onde ela iniciou sua jornada/missão. A incorporação dos lugares de memória como espaços de apreciação do legado cultural tende a se tornar um importante elemento diferenciador da oferta turística do município. Como elemento para desenvolver o turismo religioso, ele maximiza uma particularidade, promovendo o seu conhecimento e sua preservação por meio de uma prática de turismo capaz de agregar valor à experiência dos visitantes (CARVALHO, 2011).

\footnotetext{
${ }^{25}$ Entrevista de Olga Braga a Daniel Barjas que integra o documentário editado no projeto "Ninho Roda o Brasil”. São Cristóvão, 2009.
} 


\section{REFERÊNCIAS}

ARAGÃO, I. R. Cultura, identidade e memória: uma análise da relação do turismo com o patrimônio arquitetônico na cidade histórica de São Cristóvão/SE. 2009. Monografia (Graduação em Turismo) - Estácio/Faculdade de Sergipe, Aracaju, 2009.

La Plaza São Francisco en la Ciudad de São Cristóvão (Sergipe): Barroco Español en Brasil ?. In: Brasil Cultural. 8. Ed. Lima: Lance gráfico S. A. C., 2011, v. 8, p. 4-9.

Análise do Marketing Religioso na Segunda Maior Romaria do Nordeste Brasileiro no Período da Quaresma. In: História Agora, v. 1, 2013, p. 22-37.

BAZIN, G. A arquitetura religiosa Barroca no Brasil. Rio de Janeiro: Record, 1983.

BRASIL. Guia de bens móveis e imóveis inscritos nos livros do tombo (1938-2009). Brasília: MinC/IPHAN, 2009.

CARVALHO, E. M. S. F. São Cristóvão e seus monumentos: 400 anos de história. São Cristóvão: Secretaria de Estadual de Educação, 1989.

CARVALHO, K. D. Lugar de memória e políticas públicas de preservação do patrimônio cultural. In: Revista Turismo Visão e Ação, v. 13, n. 2, 2011, p. 149-165.

COSTA, F. R. Turismo e patrimônio cultural: interpretação e qualificação. São Paulo: SENAC, 2009.

DIAS, R. O turismo religioso como segmento do mercado turístico. In: DIAS, Reinaldo; SILVEIRA, Emerson José Sena da. (Orgs). Turismo Religioso: ensaios e reflexões. Capinas: Alínea, 2003. p. 7-37.

FONTES, A. D. São Cristóvão: aspectos culturais. In: Proposição de inscrição da Praça São Francisco em São Cristóvão/SE na lista do patrimônio mundial. Aracaju: Secretaria do Estado da Infra-Estrutura, IPHAN, Prefeitura Municipal de São Cristóvão, 2007. 1-24. CD-ROM.

FRAGATA, T. Epistolário de Irmã Dulce. In: Revista do Instituto Histórico e Geográfico de Sergipe (IHGSE). Aracaju, n. 37, 2008, p. 341-351.

HALBWACHS, M. La memoria colectiva. Trad. de Inés Sancho-Arroyo. Zaragoza: Prensas Universitarias de Zaragoza, 2004.

MENEZES, W. A. Turismo e FASC na construção da identidade local em São Cristóvão / Sergipe. Monografia Graduação (Turismo), Faculdade de Sergipe, Aracaju, 2007.

NASCIMENTO, J. A. Sergipe e seus monumentos. Aracaju: Gráfica e Editora J. Andrade, 1981. 
NORA, P. Entre memória e história. A problemática dos lugares. In: Revista Projeto História. São Paulo: Pontifícia, Universidade Católica, n. 10, 1993. p. 7-28.

NUNES, M. T. A cidade de São Cristóvão na formação da história sergipana: da Colônia a nossos dias. In: Proposição de inscrição da Praça São Francisco em São Cristóvão/SE na lista do patrimônio mundial. Aracaju: Secretaria do Estado da Infraestrutura, IPHAN, Prefeitura Municipal de São Cristóvão, 2007. p. 1-16. CDROM.

OLIVEIRA, C. D. M. de. Turismo religioso no Brasil: construindo um investimento sociocultural. In: TRIGO, L. G. G. Análises regionais e globais do turismo brasileiro. São Paulo: Roca, 2005.

ORAZEM, R. B. Arte colonial sergipana: análise dos elementos artísticos das igrejas da Ordem Terceira e Conventual do Carmo em São Cristóvão/SE. Monografia (Licenciatura em Artes Visuais). São Cristóvão: UFS, 2006.

PERÉZ, X. P. Turismo cultural: uma visão antropológica. Tenerife, Espanha: ACA y PASOS, RTPC, 2009.

POLLAK, M. Memória e Identidade Social. Trad. Monique Augras. In: Revista dos Estudos Históricos. Rio de Janeiro: FGV/CPDOC, v. 5, n. 10, 1992. p. 1-15.

REVISTA ISTO É. Irmã Dulce - a religiosa do século. Ed. especial, n. 6, São Paulo: 2000 .

SOUZA, F. S. Arqueologia do cotidiano: Um flâneur em São Cristóvão - SE. Dissertação (Mestrado em Geografia). São Cristóvão, UFS, 2004,

THOMPSON, E. P. Costumes em comum: estudos sobre a cultura popular tradicional. São Paulo: Companhia da Letras, 1998.

Recebido em: 30-01-2015.

Aprovado em: 01-03-2015. 